"KOSALA" JIK Vol. 6 No. 1 Mei 2018

\title{
HUBUNGAN INTENSITAS SHOLAT TAHAJUD DENGAN TEKANAN DARAH
}

\author{
Diyono $^{1}$, Siyam Khotimah Musnidawati ${ }^{2}$
}

\begin{abstract}
Background and Objectives: The prevalence of hypertension in Indonesia reaches $31.7 \%$. In developing countries including Indonesia, deaths from hypertension and its complications reach $80 \%$. In addition, about $54 \%$ of stroke and $47 \%$ of heart disease in the world caused by hypertension. Although pharmacological and non-pharmacological hypertension management efforts have been done, but the incidence of hypertension and its complications tend to increase, so there is a need to research for more therapeutic alternatives. The purpose of this study was to determine the effect of tahajud prayer therapy on blood pressure in hypertensive clients.

Methods and Subjects Research: Quasy Experiment research with one group pre test post test design. Subject of research 28 respondents taken by simple random sampling.

Results: (1) The highest percentage of hypertension is moderate hypertension category that reaches $60.7 \%$ (2) Majority or $85.7 \%$, hypertensive patients do not perform treatment or management well and regularly.

Conclusion: tahajud prayer significantly influences as a therapy to lower blood pressure.
\end{abstract}

Keywords: Hypertension, Tahajud

\section{PENDAHULUAN}

Faktor utama yang mendasari peneliti tertarik melakukan penelitian ini adalah masih tingginya angka kejadian hipertensi di masyarakat, walaupun upaya penanganan secara farmakologi dan nonfarmakologi sudah banyak dilakukan. Hal ini mendorong perlunya dicari upaya atau metode yang baru untuk mengontrol hipertensi. Hipertensi merupakan salah satu masalah yang dihadapi penduduk di Indonesia saat ini dimana pada tahun 2007 prevalensi hipertensi di Indonesia mencapai $31.7 \%$. Data menunjukkan $80 \%$ kematian akibat hipertensi terjadi di negara berkembang. Sekitar 54\% penyakit stroke dan $47 \%$ penyakit jantung di dunia disebabkan oleh hipertensi (Amran, Febrianti, dan Irawanti, 2010). Menurut WHO (World Health Organization) dan The International Society of Hypertention (ISH) yang dikutip oleh Rahajeng dan Tuminah (2009), saat ini terdapat 600 juta penderita hipertensi di seluruh dunia, dan 3 juta diantaranya meninggal setiap tahunnya. Prevalensi kasus hipertensi primer atau esensial di Provinsi Jawa Tengah tahun 2013 sebesar $67.00 \%$ mengalami penurunan dibandingkan dengan tahun 2012 sebesar 67.57\% (Dinkes Provinsi Jawa Tengah, 2013). Salah satu laporan kasus hipertensi di Eks Karesidenan Surakarta, yaitu di Puskesmas Sangkrah Surakarta pada tahun 2010 sebanyak 1.366, pada tahun 2011 sebanyak 1.456 , dan pada tahun 2012 sebanyak 2.564 (Nugraha, 2013).

Penelitian terkait upaya penatalaksanaan hipertensi dewasa ini sudah cukup banyak. Penelitian Purwati, Suryani, dan Supriyono tahun 2012 merekomendasikan relaksasi Benson efektif sebagai pendamping pengobatan farmakologis untuk membantu menurunkan tekanan darah (t-test, $\mathrm{p}=0.000)$. Penelitian Hermanto (2014) menunjukkan terapi meditasi dapat dijadikan sebagai salah satu alternatif intervensi yang dapat dimanfaatkan oleh tenaga 
kesehatan, khususnya perawat di panti wreda sebagai terapi nonfarmakologi untuk membantu menurunkan tekanan darah. Penelitian Diyono dan Mawarni (2015) memberikan bukti empiris bahwa terapi musik secara signifikan dapat menurunkan tekanan darah pada pasien hipertensi ( $t$-test, $p=0.000)$. Hasil penelitian lain terkait terapi nonfarmakologi adalah hasil penelitian Dwiastuti dan Yulianingrum (2016) memberikan bukti terapi healing touch berpengaruh terhadap penurunan tekanan darah (sistolik dan diastolik) pasien hipertensi (uji Wilcoxon, $p$ value $=0.000)$. Hasil penelitian Yanti, Mahardika dan Prapti (2016) menyimpulkan pemberian slow deep breathing berpengaruh secara signifikan terhadap penurunan tekanan darah pada penderita hipertensi.

Beberapa penelitian terkait manfaat sholat tahajud adalah penelitian Awaluddin (2016), menunjukkan bahwa ada hubungan antara pengetahuan dan shalat terhadap tekanan darah pada lansia. Penelitian Azam dan Abidin (2015), menunjukkan adanya penurunan tingkat stres individu setelah melakukan shalat tahajud dibandingkan dengan sebelum melakukan sholat tahajud. Penelitian lain adalah dari Widiani dan Indrawan (2014) memberikan bukti adanya pengaruh shalat tahajud terhadap depresi pada siswa di Pesantren An-Nur 2 Bululawang Malang. Penelitian Wardani, Nashori dan Uyun (2016), juga menunjukkan bahwa pelatihan sholat khusyuk efektif menurunkan kecemasan lansia hipertensi dengan $\mathrm{F}=75.075$ dan $p=0.00(p<0.05)$.

Penelitian ini berupaya menemukan metode baru sebagai terapi komplementar atau alternatif untuk klien hipertensi selain metode yang sudah ada selama ini. Metode yang akan peneliti buktikan efektifitas atau pengaruhnya adalah dengan metode sholat tahajud.

\section{TUJUAN PENELITIAN}

Mengetahui pengaruh sholat tahajud terhadap tekanan darah pada pasien hipertensi.

\section{METODE PENELITIAN}

Merupakan penelitian Quasy Experiment dengan one group pre test post test design.

\section{POPULASI, SAMPEL, DAN TEKNIK SAMPLING}

Populasi penelitian adalah 35 pasien hipertensi, namun sampai dengan akhir penelitian responden yang memenuhi kriteria adalah 28 responden. Teknik sampling menggunakan simple random sampling.

\section{HASIL PENELITIAN}

1. Karakteristik Responden

Tabel 1.

Distribusi Frekuensi Responden Berdasar Jenis Kelamin dan Umur

\begin{tabular}{|c|c|c|}
\hline Variabel & $\dagger$ & $\%$ \\
\hline Jenis Kelamin & & \\
\hline Laki - Laki & 11 & 39.3 \\
\hline Perempuan & 17 & 60.7 \\
\hline Umur & & \\
\hline $40-50$ & 12 & 42.9 \\
\hline $51-60$ & 12 & 42.9 \\
\hline$>60$ & 4 & 14.2 \\
\hline
\end{tabular}

Karakteristik responden berdasar jenis kelamin dan umur sesuai tabel 1 memberikan informasi responden perempuan adalah $60.7 \%$ lebih banyak dari responden laki - laki yang hanya 39.3. Sedangkan untuk kategori umur menunjukkan mayoritas responden berada pada ketegori umur 40 - 50 tahun dan 51 - 60 tahun yaitu dengan persentase yang sama yaitu $42.9 \%$ dan yang paling sedikit adalah pada 
kategori umur lebih dari 60 tahun yaitu $14.2 \%$.

Tabel 2.

Distribusi Frekuensi Tingkat Pendidikan dan Pekerjaan

\begin{tabular}{lcl}
\multicolumn{1}{c}{ Variabel } & $\mathrm{f}$ & $\%$ \\
\hline Tingkat & & \\
Pendidikan & & \\
TL SD & 3 & 10.7 \\
SD & 22 & 78.6 \\
SMP & 2 & 7.1 \\
SMA/SMK & 1 & 3.6 \\
Pekerjaan & & \\
Buruh & 13 & 46.4 \\
Swasta & 6 & 21.4 \\
Petani & 7 & 25.0 \\
Pedagang & 1 & 3.6 \\
IRT & 1 & 3.6 \\
\hline
\end{tabular}

Tabel 2 menunjukkan kategori pendidikan terakhir responden terbanyak adalah tingkat pendikan SD yaitu $78.6 \%$. Sedangkan jumlah yang paling sedikit adalah pada kategori tingkat pendidikan SMA sebesar $3.6 \%$ sedang yang pendidikan tinggi tidak ada. Mayoritas responden bekerja sebagai buruh yaitu $46.4 \%$ sedang yang paling sedikit adalah ibu rumah tangga dan pedagang yaitu $3.6 \%$. Hal ini sesuai dengan karakteristik demografi pengambilan data yang dekat dengan pabrik sehingga kebanyakan responden bekerja sebagai buruh pabrik.

2. Pengobatan Hipertensi

Tabel 3.

Distribusi Frekuensi

Pengobatan Hipertensi

\begin{tabular}{ccc}
\hline Pengobatan & $\mathrm{f}$ & $\%$ \\
\hline Teratur & 4 & 14.3 \\
Tidak Teratur & 24 & 85.7 \\
\hline Jumlah & 28 & 100 \\
\hline
\end{tabular}

Tabel 3 menunjukkan secara umum hipertensi pada masyarakat Ngelom Jaten Karanganyar belum dikelola dengan baik, dimana yang diberi pengobatan dan kontrol secara teratur hanya $14.3 \%$.

3. Kategori Hipertensi

Tabel 4.

Distribusi Frekuensi

Kategori Hipertensi

\begin{tabular}{lcccc}
\hline \multirow{2}{*}{ Kategori } & \multicolumn{2}{c}{ Pre } & \multicolumn{2}{c}{ Post } \\
\cline { 2 - 5 } & $\mathrm{f}$ & $\%$ & $\mathrm{f}$ & $\%$ \\
\hline Normal Tinggi & 0 & 0.0 & 11 & 39.3 \\
Ringan & 8 & 28.6 & 17 & 60.7 \\
Sedang & 17 & 60.7 & 0 & 0.0 \\
Berat & 3 & 10.7 & 0 & 0.0 \\
Sangat Berat & 0 & 0.0 & 0 & 0.0 \\
\hline \multicolumn{1}{c}{ Jumlah } & 28 & 100 & 28 & 100 \\
\hline
\end{tabular}

Karakteristik kategori tekanan darah seperti tertulis pada tabel 4 menunjukkan pada awal pengukuran (pre) persentase hipertensi yang paling banyak adalah pada kategori sedang yaitu $60.7 \%$ sedangkan pada saat pengukuran akhir (post) persentase terbanyak pada kategori ringan yaitu $60.7 \%$.

4. Pengaruh Sholat Tahajud

Tabel 5.

Hasil Paired T-Test

\begin{tabular}{ccc}
\hline \multirow{2}{*}{ Pengukuran } & \multicolumn{2}{c}{ Nilai } \\
\cline { 2 - 3 } & $\mathrm{t}$ & Statistik \\
\hline Sistole & 8.04 & 0.001 \\
Diastoled & 4.92 & 0.001 \\
\hline
\end{tabular}

Hasil Paired T-Test seperti terlihat pada tabel 5 menunjukkan bahwa nilai sig (2 tailed) untuk sistolik dan diastolik adalah $0.001 \quad(<0.005)$ sehingga dapat disimpulkan terdapat perbedaan atau ada pengaruh sholat tahajud terhadap tekanan darah.

\section{PEMBAHASAN}

Hasil penelitian menunjukkan sebelum diberi perlakuan tekanan darah responden yang termasuk kategori sedang adalah paling banyak $60.71 \%$, ringan $28.57 \%$, dan bahkan ada yang termasuk kategori berat sebanyak $10.71 \%$. Tekanan darah merupakan gambaran 
seberapa tinggi tekanan yang ada di penampang pembuluh darah arteri seseorang. Tekanan darah secara definitif merupakan tenaga yang diupayakan oleh darah untuk melalui setiap unit dinding vaskular. Tekanan sistolik adalah tekanan tertinggi dalam arteri akibat dorongan darah yang masuk kedalamnya berkaitan dengan kekuatan kontraksi otot jantung. Tekanan diastolik adalah tekanan terendah selama periode relaksasi jantung (Udjianti, 2011). Tekanan darah tersebut dapat diukur dengan suatu alat yang kemudian dituliskan dalam bentuk angka atau nilai sistolik dan diastolik. Sebagaimana fungsi tubuh yang lain tentunya tekanan darah juga dapat mengalami gangguan berupa tekanan darah lebih tinggi dari nilai normal yang sering dikenal dengan hipertensi. Menurut Aspiani (2014), hipertensi dapat didefinisikan sebagai tekanan darah persisten dimana tekanan sistoliknya di atas $140 \mathrm{mmHg}$ dan tekanan darah diastolik di atas $90 \mathrm{mmHg}$.

Hasil penelitian juga menunjukkan dari seluruh responden hanya ada $14.3 \%$ responden yang melakukan pengobatan atau pengelolaan hipertensi secara teratur dan $85.7 \%$ tidak melakukan pengelolaan dengan baik atau teratur. Data tersebut memberikan bukti bahwa angka kejadian hipertensi di masyarakat memang cenderung meningkat dan banyak diantara pasien tidak melakukan pengobatan atau penatalaksanaan hipertensi secara baik. Hasil ini sesuai dengan laporan WHO (World Health Organization) dan the International Society of Hypertention (ISH) yang dikutip oleh Rahajeng dan Tuminah (2009), dimana jumlah penderita hipertensi di seluruh dunia terus meningkat dan tujuh dari 10 penderita atau $70 \%$ dari penderita tersebut tidak mendapatkan pengobatan secara adekuat.
Hipertensi juga sering dikenal dengan silent killer atau pembunuh yang tidak kedengaran, karena hipertensi pada umumnya tidak menunjukkan gejala-gejala klinis yang jelas namun tiba-tiba dapat menyebabkan komplikasi yang cukup berat bahkan dapat terjadi kematian.

Hasil penelitian ini menunjukan keterkaitan implikasi atau dampak hipertensi yang tidak terkontrol dengan baik dapat menyebabkan tekanan darah cenderung semakin meningkat sehingga masuk pada ketegori hipertensi sedang atau berat. Menurut Lewis, Heitkemper dan Dirksen sebagaimana dikutip oleh Triyanto (2014), dalam algoritme penanganan hipertensi, pada dasarnya hipertensi dapat dikontrol dengan terapi nonfarmakologi seperti modifikasi gaya hidup termasuk menurunkan obesitas, pengelolaan stress dan kecemasan melalui olahraga dan aktivitas yang dapat menciptakan keadaan rileks, serta mengurangi asupan garam merupakan langkah awal yang harus dilakukan. Namun hasil penelitian menunjukkan baru sedikit dari warga yang melakukan hal-hal di atas untuk mengontrol hipertensinya, sehingga jumlah responden yang mengalami hipertensi kategori sedang sangat banyak.

Pada penelitian ini perlakuan atau terapi yang diberikan pada pasien hipertensi adalah sholat tahajud selama kurang lebih 4 minggu dengan durasi minimal 3 kali dalam setiap minggu, dengan waktu pada sepertiga malam kedua dan ketiga (pukul 01.00 - 04.00). Peneliti tidak menemui kendala untuk memberikan terapi tersebut karena pada umumnya responden adalah muslim dan beberapa sudah mengerti manfaat sholat tahajud dari segi spiritual muslim. Sehingga pada saat diberi anjuran atau penjelasan tentang manfaat sholat 
tahajud untuk kesehatan pada umumnya responden semakin termotivasi untuk melakukan sholat tahajud.

Hasil penelitian menunjukkan secara signifikan terapi sholat tahajud efektif menurunkan tekanan darah, dimana hasil $t$-test menunjukkan $p=0.001$ baik untuk sistolik maupun diastolik. Nilai ratarata tekanan darah sistolik setelah perlakuan 138.21 lebih rendah daripada sebelum perlakuan (162.85) juga memberikan bukti bahwa sholat tahajud efektif menurunkan tekanan darah sistolik. Demikian juga untuk tekanan darah diastolik nilainya juga menunjukkan penurunan dari 95.71 turun menjadi 85.00. Hasil tersebut memberikan bukti bahwa secara statistik sholat tahajud dapat menurunkan tekanan darah.

Hasil analisis univariat juga memperkuat bukti bahwa sholat tahajud efektif untuk menurunkan tekanan darah. Tekanan darah paling tinggi sebelum perlakuan adalah 190/110 mmHg sedangkan setelah perlakuan menurun menjadi $150 / 100 \mathrm{mmHg}$. Tekanan darah pada kelompok minimum juga menunjukkan penurunan dimana sebelum perlakuan adalah 140/80 $\mathrm{mmHg}$ menurun menjadi 130/70 mmHg. Menurut Aspiani (2014), pada umumnya hipertensi tidak memiliki penyebab yang spesifik, hipertensi terjadi sebagai respon peningkatan cardiac output atau peningkatan tahanan perifer pembuluh darah. Sesuai konsep tersebut hipertensi primer pada dasarnya terjadi karena peningkatan kardiak output yang terjadi karena denyut jantung meningkat. Menurut Kozier, et al. (2010) salah satu faktor yang mempengaruhi tekanan darah adalah stres psikologis. Stres psikologis secara neuro endokrin akan memberikan stimulasi sistem pada saraf simpatis sehingga merangsang hormon katekolamin.
Peningkatan hormon ini akan menyebabkan peningkatan kontraksi jantung sehingga heart rate akan meningkat yang pada akhirnya dapat meningkatkan tekanan darah. Menurut Triyanto (2014) algoritma penanganan hipertensi non-farmakologis, terapi non-farmakologis harus diberikan kepada semua pasien hipertensi primer dengan tujuan menurunkan tekanan darah dan mengendalikan faktor risiko serta penyakit penyerta lainnya. Ketidakpatuhan pasien terhadap modifikasi gaya hidup yaitu konsumsi alkohol, pengendalian berat badan, termasuk pengendalian stres dan kecemasan merupakan salah satu penyebab terjadinya hipertensi resisten. Berbagai cara untuk menciptakan keadaan rileks dengan terapi relaksasi seperti meditasi, yoga atau hypnosis yang dapat mengontrol sistem saraf, sehingga dapat menurunkan tekanan darah. Manejemen stress melalui teknik relaksasi dan biofeedback dapat menurunkan tekanan darah dalam jangka pendek maupun jangka panjang. Pemeriksaan tekanan darah secara rutin, terapi komplementer (terapi musik, yoga, herbal) dan terapi relaksasi progresif dapat mengendalikan tekanan darah.

Sholat tahajud adalah sholat sunah di waktu malam hari. Pada bulan Romadhon sholat ini disebut dengan shalat tarawih atau qiyamu ramadhan (Natary, 2015). Berbeda dengan sholat tahajud di bulan Romadhon, maka sholat tahajud di bulan-bulan yang lain dikerjakan setelah terlebih dahulu tidur malam. Selain bermanfaat secara ruhiyah ternyata sholat dapat memberikan manfaat secara jasadiyah. Dengan demikian, sholat tahajud yang dilakukan ditengah malam, disaat kebanyakan manusia terlelap dalam tidurnya dan berbagai aktivitas hidup berhenti, serta suasana begitu 
hening, sunyi dan tenang, sangat menunjang konsentrasi seseorang yang akan (ber-taqarrub) kepada Allah sehingga dapat menurunkan ketegangan mental atau stres psikologis (Kurniasih, 2013 ). Sesuai konsep tersebut maka sholat tahajud dapat menurunkan stres psikologis sebagai faktor utama penyebab hipertensi primer.

Hasil penelitian ini sesuai dengan hasil penelitian terdahulu Awaluddin (2016), dengan judul hubungan pengetahuan dan sholat terhadap tekanan darah pada lansia hipertensi di Balai Pelayanan Sosial Tresna Werdha (BPSTW) Khusnul Khotimah Pekanbaru, yang menyimpulkan bahwa ada hubungan antara pengetahuan dan sholat terhadap tekanan darah pada lansia. Demikian pula penelitian Azam dan Abidin (2015), dengan judul penelitian efektivitas sholat tahajud dalam mengurangi tingkat stres santri Pondok Islam Nurul Amal Bekasi Jawa Barat menunjukkan bahwa hasil pretest dan posttest kelompok eksperimen menunjukkan adanya penurunan tingkat stres individu setelah melakukan sholat tahajud dibandingkan dengan sebelum melakukan sholat tahajud. Penelitian lain adalah penelitian dari Widiani dan Indrawan (2014), yang berjudul pengaruh sholat tahajud terhadap depresi pada santri di pesantren An-Nur 2 Bululawang Malang, dimana dengan analisis uji Wilcoxon $\alpha=0.05$ diperoleh nilai $p$ 0.027 sehingga $<0,05$ yang berarti ada pengaruh sholat tahajud terhadap depresi pada siswa di pesantren An-Nur 2 Bululawang Malang. Penelitian Wardani, Nashori dan Uyun (2016) yang berjudul efektivitas pelatihan sholat khusyuk dalam menurunkan kecemasan pada lansia hipertensi juga menunjukkan bahwa pelatihan sholat khusyuk efektif menurunkan kecemasan lansia hipertensi dengan $F=75.075$ dan $p=0.00(p<0.05)$.

Selain itu menurut Arbain (2017), gerakan rukuk dan sujud dalam sholat yang dilakukan dalam jangka waktu yang agak lama memiliki manfaat yang baik untuk kesehatan fungsi hati dan urat nadi. Selain itu, gerakan-gerakan shalat juga mampu mengurangi resiko tekanan darah tinggi. Gerakan-gerakan yang ada dalam sholat bermanfaat bagi peredaran darah dan kesehatan hati. Gerakan-gerakan sholat juga berfungsi untuk mengurangi resiko terputusnya pembuluh darah dan mengurangi resiko terganggunya kinerja organ hati. Kriteria sholat tahajud yang diberikan ke responden pada penelitian ini adalah 11 (sebelas) rekaat, dengan 4 (empat) kali masing masing 2 (dua) rekaat salam lalu dilanjutkan 3 (tiga) rekaat sholat witir. Sesuai batasan tersebut walaupun peneliti membebaskan surat yang dibaca oleh responden maka waktu yang dibutuhkan setiap kali sholat tahajud adalah sekitar 30-45 menit. Dengan rentang waktu tersebut maka setiap responden akan melakukan gerakan-gerakan sholat secara teratur dengan periode waktu yang cukup lama, sehingga dapat melatih otot-otot jantung untuk melakukan pompa jantung secara sikardian dan memungkinkan denyut nadi teratur dan tekanan darah menjadi normal. Berdasar uraian-uraian tersebut mempertegas bahwa sholat tahajud yang dilakukan secara khusyuk dan kontinyu dapat membantu menurunkan stres psikologis dan kecemasan sehingga pompa jantung menjadi lebih efektif yang pada akhirnya dapat menurunkan tekanan darah.

\section{KESIMPULAN}

1. Persentase hipertensi yang paling banyak adalah kategori hipertensi sedang yaitu mencapai $60.7 \%$. 
2. Mayoritas penderita hipertensi tidak melakukan pengobatan atau pengelolaan secara baik dan teratur yaitu $85.7 \%$.

3. Sholat tahajud berpengaruh secara signifikan sebagai terapi untuk menurunkan tekanan darah.

\section{SARAN}

1. Perawat diharapkan dapat meningkatkan kesadaran pasien hipertensi untuk mengelola hipertensi dengan baik.

2. Masyarakat dapat menggunakan sholat tahajud sebagai terapi komplementer hipertensi.

3. Untuk peneliti selanjutnya diharapkan dapat melakukan penelitian yang lebih komprehensif tentang pengaruh sholat tahajud dengan memperbanyak responden dan menambah waktu pengumpulan data.

\section{DAFTAR PUSTAKA}

Amran, Y., Febrianti, dan L. Irawanti. 2010. "Pengaruh Tambahan Asupan Kalium dari Diet terhadap Penurunan Hipertensi Sistolik Tingkat Sedang pada Lanjut Usia", Jurnal Kesehatan Masyarakat Nasional. Volume 5. Nomor 3. Jakarta. Diakses pada 29 November 2017 pukul 20.05 WIB.

Arbain, M. 2017. Shalat For Theraphy. Pustaka IImu Group, Yogyakarta.

Aspiani, R. Y. 2015. Buku Ajar Asuhan Keperawatan Klien Gangguan Kardiovaskular Aplikasi NIC \& NOC. Penerbit Buku Kedokteran EGC, Jakarta.

Awaluddin, Y. 2016. Hubungan Pengetahuan dan Shalat Terhadap Tekanan Darah Pada Lansia, Jurnal Endurance. 1. Pekanbaru, Riau. Diunduh 01 Oktober2017.http://ejournal.kop ertis10.or.id/index.php/enduranc e/article/view/1533/472.

Azam, Mohammad Sabiq dan Zaenal Abidin. 2015. Efektivitas Sholat Tahajud dalam Mengurangi Tingkat Stress Santri Pondok Islam Nurul Amal Bekasi Jawa Barat, Jurnal Empati. 4. Semarang. Diunduh $01 \quad$ Oktober 2017. http://jurnal.uii.ac.id/index.php/in tervensipsikologi/article/view/38 89/3464.

Dinkes Provinsi Jawa Tengah. 2014. Profil Kesehatan Provinsi Jawa Tengah tahun 2013. Dinkes Provinsi Jawa Tengah, Semarang. Diakses pada 7 Oktober 2017 pukul 18.03 WIB.

Diyono dan Mawarni. 2015. "Efek Terapi Musik Untuk Menurunkan Tekanan Darah Pada Pasien Hipertensi Di Desa Taraman Sragen Jawa Tengah". Jurnal IImu Kesehatan Kosala. Volume 3 No. 2 September.

Dwiastuti dan Yulianingrum. 2016. "Pengaruh Terapi Healing Touch Terhadap Perubahan Tekanan Darah Pasien Hipertensi Di Desa Tulakan Donorojo Jepara" ejr.stikesmuhkudus.ac.id/index. php/jikk/article/download/111/60 3. Diakses pada tanggal 17 Desember 2017.

Hermanto J. 2014. "Pengaruh Pemberian Meditasi Terhadap Penurunan Tekanan Darah Pada Lansia Dengan Hipertensi Di Unit Sosial Rehabilitasi Pucang Gading Semarang". Jurnal Keperawatan Stikes Ngudi Waluyo. 112.78.40.115/eJournal/index.php/ilmukeperawa tan/article/.../88.4. Diakses pada tanggal 22 Desember 2017.

Kozier, B., et al. 2010. Buku Ajar Fundamental Keperawatan : Konsep, Proses, dan Praktik. Edisi VII. Alih bahasa Pamilih 
Eko Karyuni, et al. EGC, Jakarta.

Kurniasih, I. 2013. Tahajudlah, Allah Pasti Menolongmu!. Mutiara Media, Yogyakarta.

Natary, H. E. 2015. Shalat Tahajud Cara Rasulullah SAW. Wahyu Qolbu, Jakarta.

Nugraha, B. K. A. 2013. Hubungan Tingkat Pengetahuan Keluarga dengan Sikap Pencegahan Komplikasi pada Pasien Hipertensi di Wilayah Kerja Puskesmas Sangkrah Surakarta. Skripsi. Fakultas IImu Kesehatan UMS, Surakarta. Diakses pada 13 September 2017 pukul 08.14 WIB.

Purwati, D., Suryani, dan Supriyono M. 2012. Perbedaan Tekanan Darah Sebelum Dan Sesudah Melakukan Terapi Relaksasi Benson pada Pasien Hipertensi.Jurnal.unissula.ac.id/i ndex.php/jnm/article/download/7 89/656. Diakses pada 22 Desember 2017.

Rahajeng, E. dan S. Tuminah. 2009. "Prevalensi Hipertensi dan Determinannya di Indonesia", Majalah Kedokteran Indonesia. Volume 59. Nomor 12. Pusat Penelitian Biomedis dan Farmasi Badan Penelitian Kesehatan Departemen Kesehatan RI, Jakarta. Diakses pada 7 Oktober 2017 pukul 17.40 WIB.

Triyanto, E. 2014. Pelayanan Keperawatan bagi Penderita Hipertensi Secara Terpadu. Graha Ilmu, Yogyakarta.

Udjianti, W. J. 2010. Keperawatan Kardiovaskular. Salemba Medika, Jakarta.
Yanti, N. P., I. A. Mahardika, dan N.K.D. Prapti. 2016. "Pengaruh Slow Deep Breathing Terhadap Tekanan Darah Pada Penderita Hipertensi di Wilayah Kerja Puskesmas I Denpasar Timur". Jurnal Keperawatan dan Pemikiran Ilmiah. Program Studi IImu Keperawatan Fakultas Kedokteran Universitas Udayana. Diunduh pada 22 Desember 2017.

Wardani, Y., H. F. Nashori dan Q. Uyun. 2016. Efektivitas Pelatihan Shalat Khusyuk dalam Menurunkan Kecemasan pada Lansia Hipertensi, Jurnal Intervensi Psikologi. 8. Yogyakarta. Diunduh 01 Oktober 2017. http://www.jurnal.uii.ac.id/index. php/intervensipsikologi/article/vi ew/8030/6985.

Widiani, E. dan D. Indrawan. 2014. Pengaruh Sholat Tahajud Terhadap Depresi pada Santri di Pesantren An-Nur 2 Bululawang Malang, Jurnal CARE. 2. Malang. Diunduh 07 Oktober 2017. https://jurnal.unitri.ac.id/index.ph $\mathrm{p} /$ care/article/ view/588/576.

${ }^{1}$ Dosen Akper Panti Kosala

Surakarta

${ }^{2}$ Mahasiswa Akper Panti Kosala

Surakarta 